\title{
Technology Transfer with Moral Hazard
}

\author{
by \\ Jay Pil Choi, Columbia University
}

\section{September 1995}

1994-95 Discussion Paper Series No. 745

$$
\text { Ap }
$$




\title{
Technology Transfer with Moral Hazard
}

\author{
by \\ Jay Pil Choi*
}

July 1995

revised, September 1995

Correspondent:

Jay Pil Choi

Department of Economics

Columbia University

New York, NY 10027

U.S.A.

Tel.:212-854-5488

Fax.: 212-854-8059

E-mail: jpc8@columiba.edu

*I am grateful to Oliver Hart for his advice and encouragement for this research. The preliminary draft of this paper was written while I was visiting the Center for Economic Studies, University of Munich and the Institute for Advanced Studies in Vienna, Austria. I thank these two institutions for their hospitality during my stay. The financial support for this resuch was partly provided by the Austrian Ministry of Science and Research. 


\begin{abstract}
This paper develops an incomplete contract model of the licensing relationship that is susceptible to the moral hazard problem. The optimal contractual form of licensing derived in the model generates predictions that seem to be consistent with actual practice. For instance, the introduction of inputs that are not contractible and costly explains the prevalence of royalty contracts in the licensing relationship. Moreover, the model is able to relate the size of the royalty rate to the parameters that represent the environments under which the concerned parties operate. The framework also provides a rigorous evaluation of the recent debate on the issue of technology licensing and competitiveness in the global economy. In addition, the difficulty that the licensor faces in controlling the use of information in the development of related products in the future can explain the rationale for including grant-back clauses in licensing contracts. Finally, the model can be naturally extended to analyze the choice of a technology holder between direct investment and licensing in an attempt to serve a foreign market.
\end{abstract}




\section{Introduction}

Licensing is a voluntary form of dissemination whereby an inventor can enjoy at least some of the gains to trade by availing other parties of the use of her superior knowledge. In the theory of licensing, it is almost invariably assumed that intellectual property can be viewed as a "public good" in that the marginal cost to the owner of transmitting information and providing access to it is essentially zero compared to all of the costs involved in the creation of knowledge (see Arrow [1962]). In other words, either licensing is simply viewed as the right to infringe on patents or the knowledge is assumed to be completely codified (see Kamien [1992] for an excellent survey on patent licensing). Underlying this view is a common belief that technology is nothing but a set of blueprints usable to all at trivial cost. ${ }^{1}$

In practice, however, information is often costly to transfer to other firms because licensing frequently involves the services of the licensor's personnel to install and train the licensee's personnel. ${ }^{2}$ In a similar vein, for the licensee firms, it is insufficient merely to expose them to the relevant knowledge without their own exerted efforts to internalize such knowledge. ${ }^{3}$ This is particularly true when knowledge is less explicit and less codified. ${ }^{4}$ In the case of an international technology transfer, it may further entail adaptation of the technology to a local market. To render empirical supports, Teece (1977), for instance, reports that the costs of transferring a production process averaged 19 percent of the total costs of the project.

This paper presents a simple formal analysis of the licensing relationship under the circumstances in which effective transmission of knowledge requires costly inputs by both dispensing and receiving parties. Incorporating these elements in the technology transfer process will be shown to shed some light on issues that cannot be handled in more conventional models of licensing. These include, in particular, the prevalence of royalty contracts even in the absence of asymmetric information and the role of grant-back clauses under the threat of future competition. In addition, the optimal contractual form of licensing derived in this model generates predictions that seem to be consistent with actual practice.

The basic premise of the paper is that the costly inputs needed for effective transmission of knowledge cannot be contracted directly. These costly inputs include the efforts exerted in

\footnotetext{
${ }^{1}$ For instance, Grossman and Helpman (1991) assume that ideas and knowledge flow costlessly and instantaneously across national boundaries.

${ }^{2}$ For instance, Barton et al. (1988) claim that substantial teaching and training are usually necessary for technology to be transferred effectively.

${ }^{3}$ See Kim (1993) for a discussion on absorptive capacity and its role in Korea's industrial growth.

${ }^{4}$ Berrill (1964) points out that "only the broad outlines of technical knowledge are codified by nonpersonal means of intellectual communication".
} 
the transfer process by either party, which may not be observable to the other party. Or they may be observable to the parties in the relationship but not verifiable to a third party. Henceforth, they are not enforceable in court. This implies that the process of technology transfer is susceptible to the moral hazard problem. In this situation, I analyze how the optimal contractual form of licensing should be structured. I assume that the contract can specify the lump-sum payment and/or royalty fee which depends on the verifiable quantity produced by using the technology licensed, and may specify the allocation of property rights on any forthcoming improvement based on the licensed technology. The analysis also sheds some light on how the choice between licensing and direct foreign investment (DFI) as a vehicle to serve a foreign market is made. It is shown that the two alternative ways of penetrating the foreign market present different investment incentives for the two parties involved in the technology transfer process . The choice, consequently, depends on the relative importance of the investments by the two parties in the relationship.

The incomplete contract framework developed in this paper can also be applied to the case where the incompleteness of the contract stems from the fact that the nature of knowledge to be transferred is not well-defined that it cannot be specified exactly in the contract; the technology concerned contains a high tacit component which is informal and less codified. In this case, there may be conflicts in the type of technology that is actually delivered and the one that is desired to be delivered unless the contract is designed to be incentive-compatible. The analysis here provides a new perspective on the relationship between international technology transfer and competitiveness in the global economy. One commonly made claim in relation to the international competitiveness issue is that the licensing of cutting-edge technologies can lead to the loss of competitive advantage for the licensor. This, in turn, prompted a popular view that sees the licensing of frontier technologies to foreign firms as a cardinal sin from the perspective of protectionists. In this regard, it may seem natural that we witness tendencies to withhold the best technologies by U.S. firms. How plausible this explanation may be, the logic behind the argument, however, contains gaps because it begs the question of why the licensing firm cannot negotiate and extract more surplus if there is any additional gains for the licensee in future competition due to the transfer of the frontier technology. The incomplete contract approach in this paper will make explicit the mechanism by which the transfer of cutting-edge technology is hindered. Then, I demonstrate how the grant-back clause can relax the incentive compatibility constraint and can facilitate the transfer of the best technology available.

In spirit, this paper is closely related to a recent paper by Aghion and Tirole (1994) who 
open the black box of "the management of innovation" from an organizational point of view. Using the incomplete contract framework pioneered by Grossman and Hart (1986), they demonstrate that incorporating the imperfections of the innovation market explicitly in the analysis can generate useful insights on the management of innovation. The analysis of technology transfer in this paper is another step in that direction.

The problem arising in this paper is also related to "moral hazard in teams" analyzed by Holmstrom (1982). The focus of his paper, however, is rather different. He emphasizes the central role of a principal who can break the balanced-budget constraint and enforce group punishment self-imposed by the team members in order to prevent the free-rider problem. In the context of the licensor-licensee relationship, it is not obvious who can play the role of the principal. More importantly, his analysis is of limited value in the licensing relationship because the profits from technology transfer may be fungible by the licensee. Unless the profit from using the licensed technology is directly verifiable, the optimal incentive scheme in Holmstrom may be inapplicable.

Finally, Gallini and Wright (1990) provide an analysis of licensing in the presence of asymmetric information. They explain the royalty rate in the contract as a signaling device for the licensor. In contrast, my model focuses on the moral hazard problem. The relative applicability of these two models will depend on the circumstances under which licensing takes place. Therefore, these two models should be viewed as complementary rather than competing.

The remainder of the paper is organized in the following way. In section II, I set up a basic model. Section III uses the basic framework to analyze the choice between DFI and licensing. The choice is shown to depend crucially on the relative importance of investment efforts by the licensor and the licensee. Section IV concerns the dynamic consequences of licensing and provides a rationale for the inclusion of the so-called grant-back clause. Section $\mathrm{V}$ contains concluding remarks.

\section{The Model}

I consider a technology transfer between two firms located in two different countries. I assume that these two national markets are segmented. Therefore, there is no direct competition between the licensor and the licensee in the same market. This assumption spares an analysis of the competitive effect of licensing. ${ }^{5}$ I also assume that the technology is already established

${ }^{5}$ Licensing to other firms operating in the same market invites tough competition and lowers the industry's profit. Katz and Shapiro (1985) analyzes the conditions under which licensing increases the industry's profit and, therefore,licensing occurs between firms in the same market. 
and the commercial value of it is proven in the licensor's country when the licensing takes place. Therefore, there is no informational asymmetry regarding the value of technology. 6 In addition, I assume that the technology is licensed to only one firm in a given market. ${ }^{7}$ This is consistent with the assumption of costly technology transfer, which can be regarded as a fixed cost of production.

Contrary to a common belief that technology transfer is costless, the value of resources that have to be employed to ensure a successful transfer of technology can be substantial. 8 Accordingly, I depart from the previous literature in assuming that the effective transfer of technology entails both transmission and absorption costs incurred by the licensor and the licensee, respectively. This leads me to assume that there are two indispensable and relationship-specific investments provided by the licensor and the licensee. Let $\sigma$ and $\beta$ denote the efforts supplied by the licensor and the licensee, respectively, in the process of technology transfer. The candidates for $\sigma$ include pre-start-up training costs and advisory services provided by the licensor to expedite the licensee's acquisition of technological capability. Similarly, $\beta$ represents the effort of the licensee to assimilate the foreign technology to a local market. ${ }^{9}$ Kim and Dahlman [1992], for instance, report that local efforts to assimilate, adapt and improve imported technology are crucial to successful technology transfer.

I assume that the constant marginal cost realized after technology transfer can be written as $c(\beta, \sigma)$ with $\partial c(\sigma, \beta) / \partial \sigma<0$ and $\partial c(\sigma, \beta) / \partial \beta<0$. It is assumed that $\sigma$ and $\beta$ are not contractible. The contract can be contingent only on the verifiable quantity of the product that incorporates the licensed technology. Let me denote $\pi(c)$ as the (reduced) profit function when the constant marginal cost is given by c. Both parties are assumed to be risk-neutral and have reservation utility of zero.

Let $\sigma^{*}$ and $\beta^{*}$ be the first-best effort levels for the licensor and the licensee. They are derived from

$$
\underset{\sigma, \beta}{\operatorname{Max}} \pi[c(\sigma, \beta)]-\sigma-\beta
$$

The first-order condition for optimality is given by:

$$
\pi^{\prime}\left[c\left(\sigma^{*}, \beta^{*}\right)\right] \frac{\partial c\left(\sigma^{*}, \beta^{*}\right)}{\partial \sigma}=\pi^{\prime}\left[c\left(\sigma^{*}, \beta^{*}\right)\right] \frac{\partial c\left(\sigma^{*}, \beta^{*}\right)}{\partial \beta}=1
$$

\footnotetext{
${ }^{6}$ Gallini and Wright (1990) deal with the issue of informational asymmetry in the licensing relationship. 7 This assumption is in accord with Firestone's (1971) finding that most licenses are sold to a single firm. 8 In Teece's (1977) study on 26 international technology projects, the transfer costs ranged from $2 \%$ to $59 \%$ of total project cost.

${ }^{9}$ See Teece (1977) for categorization of technology transfer costs.
} 
If a complete contract can be written, the first best outcome can easily be attained. Suppose that there are many potential licensees. As a result, the licensor has the bargaining power and makes a take-it-or-leave-it offer to the licensee. The distribution of the bargaining power has no consequences for efficiency in my framework since I do not assume any cash constraint for either party. 10 Then, the optimal contract specifies $\sigma^{*}$ and $\beta^{*}$ and all the surplus from the licensing relationship will be extracted by a fixed fee. Note that if a complete contract can be written ( $\sigma$ and $\beta$ are contractible), the optimal contract requires the royalty rate to be set at zero. The reason is that the royalty rate artificially changes the licensee's effective marginal cost (MC) different from the true $\mathrm{MC}$ and thereby induces an inefficient production decision.

In practice, however, licensing contracts are predominantly royalty-based. 11 This discrepancy with empirical data can be reconciled by assuming that inputs for technology transfer are not contractible. If the effectiveness of technology transfer depends on the efforts provided by both parties and these efforts are not contractible, the first-best outcome cannot be implemented. I assume that the contract can specify only the output-dependent royalty fee and any lump-sum transfer. In this case, it will be shown that the optimal licensing contract includes a royalty rate, which serves as a hostage to induce the licensor to exert costly efforts. 12

To see this, suppose that the licensing contract included only the fixed fee. Then, the licensor would have no incentive to exert any costly efforts in the technology transfer process; if we normalize the minimum level of efforts by the licensor and the licensee that can be enforced to be zero, we have $\sigma=0.13$ The licensee, then, maximizes

$$
\underset{\beta}{\operatorname{Max}} \pi[\mathrm{c}(0, \beta)]-\beta
$$

and the first-order condition for $\beta$ satisfies $\partial \pi[c(0, \beta)] / \partial \beta=1$.

Now suppose that the contract includes a royalty rate of $r$. Then, the effort levels for the licensor and the licensee are determined in the following way. Let $\mathrm{P}($.$) be the inverse demand$ function and $q(c)$ be the profit maximizing level of output when the marginal cost is given by $c$, i.e., $q(c)=\operatorname{argmax}[P(q) q-c q]$ and satisfies the first-order condition $P^{\prime} q+P=c$. Note that by

10 In contrast, in Aghion and Bolton (1992) and Aghion and Tirole (1994), ex ante bargaining power influences the size of the total profits as well as the distribution of them due to the cash constraint facing one of the parties to the contract.

11 According to Rostoker (1984), licensing with fixed fee alone was used only 13 percent of the time. In contrast, royalty plus fixed fee licensing was used 46 percent of time and royalty alone was used 39 percent of time.

12 If the transfer of technology is costless and, consequently multiple licenses can be given, the inefficient price effect of the royalty rate can be mitigated by competition among several licensees.

13 Alternatively, as in Aghion and Tirole (1994), the minimum level of effort could be driven by "intellectual curiosity, ego, career concerns, and prospects of informal rewards." 
the envelope theorem,

$$
\pi^{\prime}(\mathrm{c})=-\mathrm{q}(\mathrm{c})
$$

The licensor's effort level given the royalty rate $\mathrm{r}$ is derived from ${ }^{14}$ :

$$
\underset{\sigma}{\operatorname{Max}} \psi^{\mathrm{S}}(\sigma, \beta ; \mathrm{r})=\operatorname{Max}_{\sigma} \mathrm{rq}[\mathrm{c}(\sigma, \beta)+\mathrm{r}]-\sigma
$$

or

$$
\mathrm{rq}^{\prime}[\mathrm{c}(\sigma, \beta)+\mathrm{r}] \partial \mathrm{c}(\sigma, \beta) / \partial \sigma-1=0
$$

The licensee's effort level is the solution to the following maximization problem:

$$
\underset{\beta}{\operatorname{Max}} \psi^{\mathrm{B}}(\sigma, \beta ; \mathrm{r})=\underset{\beta}{\operatorname{Max}} \pi[\mathrm{c}(\sigma, \beta)+\mathrm{r}]-\beta
$$

or

$$
\pi^{\prime}[c(\sigma, \beta)+r] \partial c(\sigma, \beta) / \partial \beta-1=0
$$

The equilibrium level of effort levels, can be derived by solving (5) and (6) simultaneously, i.e.,

$$
\mathrm{rq}^{\prime}\left[\mathrm{c}\left(\sigma^{*}, \beta^{*}\right)+\mathrm{r}\right] \frac{\partial c\left(\sigma^{*}, \beta^{*}\right)}{\partial \sigma}=\pi^{\prime}\left[\mathrm{c}\left(\sigma^{*}, \beta^{*}\right)+\mathrm{r}\right] \frac{\partial c\left(\sigma^{*}, \beta^{*}\right)}{\partial \beta}=1
$$

Let $\sigma(r)$ and $\beta(r)$ be the noncooperative equilibrium levels of efforts for the licensor and licensee, respectively, given that the royalty rate is $r$. The optimal royalty rate $r^{*}$ is set to maximize the joint industry profit:

$$
\underset{r}{\operatorname{Max}} \pi[\mathrm{c}(\sigma(\mathrm{r}), \beta(\mathrm{r}))+\mathrm{r}]+\mathrm{rq}[\mathrm{c}(\sigma(\mathrm{r}), \beta(\mathrm{r}))+\mathrm{r}]-\sigma(\mathrm{r})-\beta(\mathrm{r})
$$

Using the first-order conditions for the licensor and the licensee (Eq. (5) and (6)) and (4), the derivative of the joint profit with respect to the royalty rate $r$ is given by:

$$
-\mathrm{q} \frac{\partial c}{\partial \sigma} \sigma^{\prime}+\mathrm{rq}^{\prime} \frac{\partial c}{\partial \beta} \beta^{\prime}+\mathrm{rq}=0
$$

The choice of the optimal royalty rate is based on two considerations. The first two terms in Eq.(9) represent the "incentive" effects whereas the last term represents "output contraction" effect of increasing the royalty rate. More specifically, a higher royalty rate induces more effort by the licensor since a lower cost for the licensee implies a higher royalty income for the licensor. In the Appendix, it is proved that $\sigma^{\prime}(r)$ is positive for sufficiently small positive values of $r$ if the stability condition for the equilibrium effort levels is assumed. This positive incentive effect for the licensor is represented by the first term in (9). The second term represents the effect of an increase in the royalty rate on the licensee's incentive, the sign of which is in general ambiguous. 15 Finally, the royalty rate introduces an artificial wedge

14 Superscripts $S$ and B denote the licensor (seller) and the licensee (buyer), respectively.

15 The sign will depend on, inter alia, whether $\beta$ and $\sigma$ are complementary or substitute to each other. 
between the effective $\mathrm{MC}$ and the true $\mathrm{MC}$; the effective $\mathrm{MC}$ (true $\mathrm{MC}$ +royalty rate) is increased for the licensee and as a result the output is reduced. The third term in (9) represents this negative effect of output contraction. The tradeoff between these two "incentive" and "output contraction" effects will determine the optimal royalty rate. When the left hand side of Eq. (9) is evaluated at $r=0$, it is positive since the second and the third terms disappear. This implies that for a small value of the royalty rate, the positive incentive effect for the licensor dominates the incentive effect for the licensee and the output contraction effect. Consequently, I can conclude that the optimal royalty rate is positive if I assume that the maximand of (8) is a well-defined concave function of $r$.

My model is also consistent with Taylor and Silberston's (1973) finding that royalty rates are positively related to the amount of know-how supplied and the cost of supplying it and that royalties are higher for products subject to price-inelastic demands. To see the effect of demand elasticity on the optimal royalty rate, we can rewrite the first order condition (9) as follows.

$$
\mathrm{r}^{*}=\frac{q}{q^{\prime}}\left(\frac{\frac{\partial c}{\partial \sigma} \sigma^{\prime}}{1+\frac{\partial c}{\partial \beta} \beta^{\prime}}\right)
$$

Let me assume that the demand function has a constant price elasticity of $\varepsilon=-D^{\prime} p / D$, i.e., $D(p)$ $=A p^{-\varepsilon}, \varepsilon>1$. Define $p(c)$ as the monopolist's profit maximizing choice of price when the marginal cost is given by c, i.e. $p(c)=(\varepsilon-1) c / \varepsilon$. Note that $q(c)=D(p(c))$ which implies that $q^{\prime}(c)$ $=\mathrm{D}^{\prime}(\mathrm{p}(\mathrm{c})) \mathrm{p}^{\prime}(\mathrm{c})$. Then,

$$
\mathrm{r}^{*}=-\frac{c}{\varepsilon}\left(\frac{\frac{\partial c}{\partial \sigma} \sigma^{\prime}}{1+\frac{\partial c}{\partial \beta} \beta^{\prime}}\right)
$$

Therefore, there is an inverse relationship between the elasticity of demand and the optimal royalty rate. The reason is that as demand becomes more inelastic, the negative effects of output contraction due to a higher royalty rate become smaller.

It should be mentioned that the exclusive focus on the linear royalty payment scheme in this paper does not entail any loss of generality because any outcome induced by a nonlinear schemes can be replicated by a linear one. Consider the second-best contract with a general royalty payment of $R(q)$. (I considered only the case where $R(q)=r q$ in the paper.) Let $(\widetilde{\sigma}, \widetilde{\beta}$, $\widetilde{q}$ ) be the outcome induced by this scheme. Then, it can be easily verified, by comparing the 
first-order conditions, that the same outcome can be achieved using a linear scheme with the royalty rate of $r=R^{\prime}(\widetilde{q})$ accompanied by an appropriate adjustment of the fixed fee.

Proposition 1. If a complete contract can be written, the optimal licensing contract will include only a fixed fee. If the effort levels in the transmission of knowledge cannot be contracted for, the optimal contract also includes a royalty rate which is determined by the trade-off between the "incentive" and "output contraction" effects.

Remark. The royalty contract can be susceptible to renegotiation if the efforts are expended only at the inception of a licensing relationship which lasts for a relatively long time; once the efforts are provided both parties have incentives to eliminate the royalty rate from the contract. In this case, the optimal contract can resemble a sliding royalty scheme. However, if the efforts must be provided continuously for effective operation of the licensee firm as in a service contract, renegoiation is not an issue. For example, the licensor's efforts can represent maintenance efforts over time, the promptness of the licensor's after-sales service to recurrent operational problems, and on-going training in problem-solving techniques.

It is worth mentioning complementary work by Gallini and Wright (1990) who also provide a theory as to why a royalty contract can be optimal. In their model, the innovator has private information regarding the quality of the technology that is licensed. In this case, the inclusion of a royalty rate serves as a signal of the quality of the technology. The situation considered in their paper is most appropriate when there is an independent inventor who tries to sell his technology to a firm with manufacturing capability. In this case, the technology has never been tested in the market. In other words, the moral hazard problem is responsible for the inclusion of a royalty rate in my model whereas adverse selection is the main reason in Gallini and Wright. Asymmetric information, however, is less plausible in the context of international technology transfer where the technology has already been proven in the licensor's country and therefore, the quality is more or less known to the potential licensee. 16

\section{Licensing versus Direct Investment}

Up to now I restricted the option to serve a foreign market only to licensing. An alternative way to penetrate a foreign market is to set up a subsidiary in the foreign country via

\footnotetext{
16 If there is any asymmetric information in our context, the chances are that the licensee would have
} superior information regarding local market conditions. 
direct investment. The framework can be naturally extended to analyze a firm's decision to serve a foreign market by licensing or direct foreign investment (DFI). Let me assume that even with direct investment through a subsidiary, a local manager is indispensable for the successful operation of the subsidiary. We interpret $\beta$ as investments by a locally recruited manager. In this context, $\beta$ includes efforts to adapt the technology to local market conditions, clear local government regulations, and aid the enforcement of intellectual property rights of the parent company, etc. With direct investment, however, the benefits of investment by a local manager accrue to the multinational firm. Therefore, the local manager has no incentive to exert efforts; investment in $\beta$ will be zero. The multinational firm maximizes

$$
\underset{\beta}{\operatorname{Max}} \pi[\mathrm{c}(\sigma, 0)]-\sigma
$$

and the first-order condition for $\sigma$ satisfies $\partial \pi[c(\sigma, 0)] / \partial \sigma=1$.

In my framework, therefore, the relative attractiveness of the two approaches to penetrating a foreign market will depend on the relative importance of $\beta$ and $\sigma$ in the technology transfer process. Licensing will be chosen over DFI if the marginal efficiency of the licensee's efforts is relatively large compared to that of the licensor's. If the licensor's effort is relatively more important in the transfer process, DFI would be favored because it is necessary to include an inordinately high royalty rate in a licensing contract to induce a proper level of licensor effort. 17 This prediction is consistent with the evidence that multinationals tend to be important in products that are technically complex (Caves [1982] and Markusen [1995]).

Proposition 2. The preferred mode of entry into a foreign market depends on the relative importance of efforts by the dispensing and receiving parties in technology transfer. Licensing is preferred to DFI if the licensee's efforts are relatively more important than the licensor's.

In a recent paper, Horstman and Markusen (1995) also compare relative merits of direct investment vs. an arm's length arrangement such as licensing in a model where a local agent possesses superior information regarding market conditions. Use of a local agent insulates the multinational firm from the downside risk of deploying assets in a market that may not be large enough to justify direct investment. However, the multinational firm has to give up informational rents to the local agent to induce self-selection. The mode of entry in their paper,

17 If profits are verifiable, DFI may involve equity participation by the licensee. In this case, the level of equity participation will also reflect the relative importance of the marginal efficiencies of the two types of efforts. 
therefore, is determined by the tradeoff between the benefits of information gathering and the cost of informational rents through the agency arrangement. They conclude that direct investment is the desirable mode of entry when the market is on average large and there is little down-side risk in expected profits. Both Horstman and Markusen's and my papers emphasize agency costs in a contractual relationship. However, the sources of agency costs differ across models. My model focuses on the moral hazard aspect of the agency relationship whereas they are interested in the adverse selection problem. ${ }^{18}$

\section{Dynamic Effects of Licensing: the "Boomerang" Effect and Grant-Back Clauses}

Huge current-account deficits, coupled with the erosion of United States' (U.S.) supremacy in the high-technology industries, have prompted both academicians and practitioners to search for ways to restore the competitive edge of the U.S. in the global market. Many theories have been put forth to explain what was responsible for the decline of U.S. competitiveness, together with prescriptions to reverse the trend [see, for instance, Dertouzos, Lester, and Solow (1989)].

Technology transfer to foreign firms has been one of the popular culprits blamed for the erosion of U.S. supremacy. In this section, I analyze the dynamic effects of licensing on the competitiveness of the licensor and examine the rationale for often observed grant-back clauses. Of particular concern are how the consideration of future competition distorts the licensing relationship and how the "grant-back" clause can mitigate this distortion. In the process, I evaluate the validity of the casual argument we often hear in relation to international technology transfer.

According to this argument, myopic U.S. firms sold their future by licensing the stateof-the-art technologies for short-term profits. As a result, they lost ground to their competitors in the succeeding generation of technological development. The VCR and the semiconductor are two prominent examples. In this context, it is not surprising to witness a recent trend to safeguard the cutting-edge technologies by the U.S. firms; once burned, they are anxious not to repeat the same mistake. As a response to this problem, it has also been suggested that a

18 I should mention that in an earlier paper, Horstman and Markusen (1987) provides a theory of the multinational's mode of entry based on agency costs due to moral hazard. In their model, there is imperfect information in the product market, which make consumers' purchase decision depend on the reputations of the products. Agency costs of licensing stem from the fact that a licensee does not fully appropriate the returns from maintaining the multinational firm's brand reputation. Their paper focus on one-sided moral hazard on the part of the licensee whereas this paper concerns two-sided moral hazard problem and the relative importance between the two. 
"technology flowback" provision in the contract that requires the licensee to share any advances or improvements in the licensed technology with the licensor, might remedy the licensor's problem of losing competitive advantage to the licensee in product development (see Shapiro (1985) and Rothstein and Willgohs [1988]). In fact, Caves et al. (1983) report that 43 percent of licensing agreements contain such grant-back clauses.

Notwithstanding the plausibility of the argument above, a closer inspection reveals that the logic behind it is incomplete in many respects. I argue that the possibility of leapfrogging by the potential licensee in and of itself cannot be the reason for withholding the frontier technologies. The reason is that if this possibility is foreseen by the parties concerned, the licensor can be potentially compensated for any future loss of competitiveness due to the technology transfer. Therefore, the current theory, if there is one, is deficient for it fails to reveal the logical steps that carry it from the possibility of leapfrogging by the licensee to the reluctance of the licensor to transfer the cutting-edge technologies.

To make my point, I first demonstrate that if a complete contract can be written, the best available technology will always be licensed simply because it enables the licensee to produce more efficiently; the first-best outcome is achieved and grant-back clauses are not necessary. This leads me to conclude that the real reason for the failure of licensing originates from the inability of the parties to the licensing relationship to write a complete contract. Without a commitment mechanism for the licensor, the contract should be incentive compatible for the best technology to be transferred in order to prevent ex post opportunism. It will be shown that if the cost of the incentive compatibility constraint (ICC) is too high, the best technology will not be transferred. Then, I analyze the mechanism by which the ICC can be relaxed with grant-back clauses.

To formalize the idea, I assume that there are two types of technology that can be licensed: the core and the peripheral technologies. The core technology differs from the peripheral technology in two respects. First, the core technology is superior to the peripheral in that it enables the licensee to produce at a lower cost; the production cost with the core technology is $\underline{c}$ while the production cost with the peripheral technology is $\bar{c}$, where $\underline{c}<\bar{c}$. In addition, the transfer of core technology may enable the licensee to develop a future generation of related product and may create a competitor to the licensor in the future. 19

\footnotetext{
${ }^{19}$ Rockett (1990) also allows the licensor to choose which versions of the technology to license when the licensor and the licensee are duopolists competing in the same market. In her paper, the quality of the licensed technology affects the licensee's ability to imitate. Different versions of the technology, however,
} 
To determine which type of technology will be transferred in the licensing relationship, it is necessary to describe the nature of future competition. To accommodate the possibility of future competition, consider a two period model (see Figure 1).

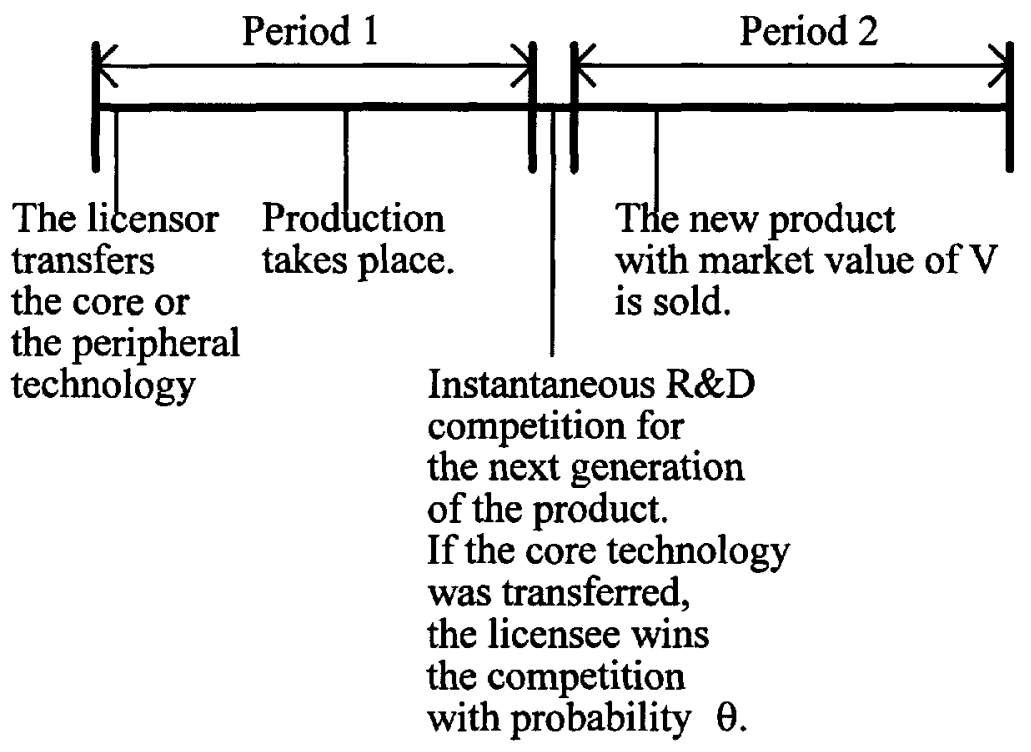

Figure 1. Timing of the Licensing and R\&D Competition.

Once there is a transfer of the core technology, there will be a race to be the first one to develop a new generation of the product which will render the old product obsolete. The new product is assumed to be sold in the second period. The $R \& D$ competition occurs in the intervening period between the end of the first period and the beginning of the second period. The value of winning the race is $\mathrm{V}$. The loser gets nothing. 20 The first one to develop captures the whole value because further entry is blocked by the patent. Alternatively, the assumption of Bertrand competition and a small sunk cost of entry will ensure no further entry.

I assume that the transfer of the core technology endows the licensee with the ability to win in the future competition with probability $\theta$. For instance, we can imagine a situation in which the licensee's hazard rate of innovation with the transfer of the core technology is given by $\lambda$, which parametrizes the ability of the licensee to absorb the technology (see Cohen and Levinthal [1989]). However, with the transfer of peripheral technology, the licensee cannot

are fully characterized by their corresponding marginal costs. Therefore, the effects of the quality of licensed technology and the grant-back clause on future product development are not considered.

${ }^{20}$ The payoff structure of "the-winner-takes-it-all" is not necessary for my argument. All we need is that the winner's payoff is larger than that of the loser and the game exhibits the feature of a race. If the payoff structure is reversed and the game is one of waiting, there is no need to worry about the transfer of the core technology. 
succeed in the development of the new technology regardless of its ability level. ${ }^{21}$ Let $\mu$ denote the hazard rate for the licensor. Then, $\theta=\lambda /(\lambda+\mu)$. Since there is a one-to-one correspondence between $\theta$ and $\lambda$, henceforth, I will parametrize the absorptive capacity with $\theta$ when the core technology is transferred.

Let $\phi_{S}^{C O R E}$ and $\phi_{B}^{C O R E}$ denote the expected future (second period) payoffs for the licensor (seller) and the licensee (buyer) when the core technology is transferred. Then, abstracting away from discounting and $R \& D$ costs, we have 22 :

$$
\phi_{S}^{C O R E}=(1-\theta) \mathrm{V}, \quad \phi_{B}^{C O R E}=\theta \mathrm{V}
$$

In contrast, with the transfer of the peripheral technology, the licensor captures the market with probability one since there is no danger of being preempted by the licensee. Therefore, the future payoffs when the peripheral technology is transferred are:

$$
\phi_{S}^{P E R I}=\mathrm{V}, \quad \phi_{B}^{P E R I}=0
$$

Let $R^{C O R E}$ (r) and $R^{P E R I}$ (r) be the royalty income for the licensor when the royalty rate is $\mathrm{r}$ :

$$
R^{C O R E}(\mathrm{r})=\mathrm{r} \mathrm{q}(\underline{c}+\mathrm{r}), R^{P E R I}(\mathrm{r})=\mathrm{r} \mathrm{q}(\vec{c}+\mathrm{r})
$$

Now suppose that a complete contract can be written specifying which type of technology will be transferred. If the core technology is transferred with the royalty rate of $r$, the payoffs for the licensor, excluding fixed fee component, are $\phi_{S}^{C O R E}+R^{C O R E}(\mathrm{r})=(1-\theta) \mathrm{V}+\mathrm{r}$ $q(\underline{c}+r)$. In addition, the licensor can extract the licensee's payoffs from the technology transfer in the form of a fixed fee, which is given by:

$$
F^{C O R E}=\pi(\underline{c}+\mathbf{r})+\theta \mathrm{V}
$$

Therefore, the licensor's payoffs with the transfer of the core technology are:

$$
\begin{aligned}
\prod^{C O R E}(\theta) & =R^{C O R E}(\mathbf{r})+F^{C O R E}+\phi_{S}^{C O R E} \\
& =\mathbf{r} \mathbf{q}(\underline{c}+\mathbf{r})+[\pi(\underline{c}+\mathrm{r})+\theta \mathrm{V}]+(1-\theta) \mathrm{V}=\mathrm{r} \mathrm{q}(\underline{c}+\mathbf{r})+\pi(\underline{c}+\mathbf{r})+\mathrm{V}
\end{aligned}
$$

$\Pi^{\text {CORE }}$ will be maximized when royalty rate, $r$, is set at zero since by using the envelope theorem, we have $\mathrm{d}[\mathrm{r} \mathrm{q}(\underline{c}+\mathrm{r})+\pi(\underline{c}+\mathrm{r})] / \mathrm{dr}=\mathrm{q}^{\prime}(\underline{c}+\mathrm{r})<0$. Since any efficiency gain by the licensee can be extracted by a fixed fee, there is no reason to distort the licensee's effective MC

${ }^{21}$ More generally, I could have assumed that the hazard rates for the licensee are given by $f(\lambda)$ and $g(\lambda)$ when the core and the peripheral technologies are transferred, respectively, without altering any qualitative results. Then, the main argument that follows will be valid if we assume that $h(\lambda)=f(\lambda)-g(\lambda)$ is increasing in $\lambda$.

22 Once again, this assumption is not crucial and is made only for expositional simplicity. We can easily construct a full-fledged R\&D model that accounts for R\&D cost and discounting without affecting any qualitative results that follow. 
by introducing a royalty rate. Therefore, the payoff for the licensor when the core technology is transferred is given by:

$$
\prod^{\mathrm{CORE}}(\theta)=\pi(\underline{c})+\mathrm{V}
$$

Note that $\prod^{\mathrm{CORE}}(\theta)$ is independent of $\theta$. The reason is that any loss of competitive advantage by the licensor will be exactly offset by the corresponding increase in the fixed fee.

Similarly, I can derive the payoffs for the licensor when the peripheral technology is transferred. The payoff for the licensee which can be extracted as a fixed fee is:

$$
F^{P E R I}=\pi(\bar{c})+\phi_{B}^{P E R I}=\pi(\bar{c})
$$

In this case also, the royalty rate will be set at zero for the same reason. Therefore, the payoff from transferring the peripheral technology is given by:

$$
\begin{aligned}
\prod^{P E R I}(\theta) & =R^{P E R I}(0)+F^{P E R I}+\phi_{S}^{P E R I} \\
& =\pi(\bar{c})+\mathrm{V}
\end{aligned}
$$

Since $\pi(\underline{c})>\pi(\vec{c})$, the licensor will always prefer to transfer the core technology. This vindicates my claim that the possibility of losing future competition alone cannot explain the nonoccurrence of technology transfer in the core technology as future competition from the licensee becomes more formidable. The intuition is quite simple. Since the licensor can extract all the surplus from the licensee via a fixed fee, the first-best outcome is achieved by maximizing the available pie in the relationship, which stipulates that the most efficient technology be transferred at the royalty rate of zero.

Proposition 3. With a complete contract, the core technology will be always transferred regardless of the consideration of future competition.

Proposition 3 suggests that the failure to transfer the core technology is a result of the inability of the concerned parties to write a complete contract. More specifically, assume that the license contract cannot specify which types of technology will be transferred. Even though which elements of the technology constitute the core component may be well-understood by the parties to the relationship, they may be difficult to convey to a third party. Consequently, what type of technology was actually transferred may not be easily verifiable in court. In this case, for the core technology to be transferred it should be incentive compatible. The incentive compatibility constraint for the licensor to transfer the core technology is: 


$$
\begin{aligned}
& R^{C O R E}(\mathrm{r})+\phi_{S}^{C O R E} \geq R^{P E R I}(\mathrm{r})+\phi_{S}^{P E R I}, \text { or } \\
& R^{C O R E}(\mathrm{r})-R^{P E R I}(\mathrm{r})=\mathrm{r}[\mathrm{q}(\underline{c}+\mathrm{r})-\mathrm{q}(\bar{c}+\mathrm{r})] \geq \theta \mathrm{V}=\phi_{S}^{P E R I}-\phi_{S}^{C O R E}
\end{aligned}
$$

In other words, the increase in royalty income by transferring the core technology should be sufficiently large to overcome the decrease in the profit due to future competition. Note that if there is no future consideration due to the transfer of the core technology (i.e., $\phi_{S}^{\text {PERI }}-\phi_{S}^{C O R E}=$ 0 ), the incompleteness of the contract does not cause any inefficiencies. Specifying any arbitrarily small royalty rate will make the transfer of the core technology to be incentive compatible. In other words, the possibility of future competition is a necessary condition for the failure of transferring the core technology to occur even though it alone cannot be a sufficient condition, as we have seen above in Proposition 3.

The effect of the royalty rate on the gap in royalty incomes between the core and the peripheral technologies can be derived as:

$$
\mathrm{d}\left[R^{C O R E}(\mathrm{r})-R^{P E R I}(\mathrm{r})\right] / \mathrm{dr}=[\mathrm{q}(\underline{c}+\mathrm{r})-\mathrm{q}(\bar{c}+\mathrm{r})]+\mathrm{r}\left[\mathrm{q}^{\prime}(\underline{c}+\mathrm{r})-\mathrm{q}^{\prime}(\bar{c}+\mathrm{r})\right]
$$

When (19) is evaluated at $\mathrm{r}=0$, it is positive; the gap in royalty incomes increases at least initially as the royalty rate becomes positive. To avoid unnecessary complications, let me assume that $\sup \left[R^{C O R E}(\mathrm{r})-R^{P E R I}(\mathrm{r})\right]>\mathrm{V} .23$ This ensures that there exists a royalty rate $\mathrm{r}$ that can satisfy the ICC for all $\theta \in[0,1]$. Let $\mathrm{r}^{*}(\theta)$ be the minimum royalty rate that satisfies the ICC. Note that the existence of a royalty rate that satisfies the ICC does not necessarily imply that the core technology will be transferred. The reason is that $r^{*}(\theta)$ is increasing in $\theta$, reflecting the fact that the ICC becomes more costly to satisfy as the possibility of leapfrogging increases. If the ICC is too costly to satisfy, the licensor may opt to transfer the peripheral technology.

When the core technology is transferred with royalty rate $r^{*}(\theta)$, the licensor extracts the payoff for the licensee via a fixed fee which is given by $\pi\left[\underline{c}+\mathrm{r}^{*}(\theta)\right]+\phi_{B}^{C O R E}$ :

$$
F^{P E R I}=\pi\left[\underline{c}+\mathrm{r}^{*}(\theta)\right]+\phi_{B}^{C O R E}=\pi\left[\underline{c}+\mathrm{r}^{*}(\theta)\right]+\theta \mathrm{V}
$$

Therefore, given the probability of losing the future competition $\theta$, the payoff for the licensor from transferring the core technology can be written as:

$$
\prod^{C O R E}(\theta)=R^{C O R E}(\mathrm{r})+F^{C O R E}+\phi_{S}^{C O R E}
$$

23 This assumption is made purely to simplify exposition and is not necessary. If this assumption is violated, there is a critical value $\bar{\theta}$ where $\sup \left[R^{C O R E}(\mathrm{r})-R^{P E R I}(\mathrm{r})\right]=\bar{\theta} \mathrm{V}$. Then, the incentive compatibility constraint can be met for all $\theta \leq \bar{\theta}$. All the analysis that follows, then, can be applied to this restricted region. 


$$
=\mathrm{r}^{*}(\theta) \mathrm{q}\left[\underline{c}+\mathrm{r}^{*}(\theta)\right]+\pi\left[\underline{c}+\mathrm{r}^{*}(\theta)\right]+\mathrm{V}
$$

When the peripheral technology is transferred, the payoff is the same as in the complete contract case since there is no additional incentive constraint to be satisfied.

$$
\prod^{P E R I}(\theta)=R^{P E R I}(0)+F^{P E R I}+\phi_{S}^{P E R I}=\pi(\bar{c})+\mathrm{V}
$$

By using the envelope theorem, I can derive

$$
\frac{d \Pi^{\text {CORE }}(\theta)}{d \theta}=\mathrm{r}^{*}(\theta) \mathrm{q}^{\prime}\left[\underline{c}+\mathrm{r}^{*}(\theta)\right] \mathrm{r}^{* \prime}(\theta)<0
$$

Since $\prod^{P E R I}(\theta)$ is constant and independent of $\theta$, there is a unique $\theta^{*}$ such that

$$
\prod^{C O R E}(\theta)>\prod^{P E R I}(\theta) \text { if and only if } \theta<\theta^{*} \text {. If no such } \theta^{*} \text { exists, set } \theta^{*}=1 \text {. }
$$

This result can explain why there will be less transfer of the core technology as the capability of the licensee to develop a new product increases. It can also be shown that, given the ability of the licensee $\theta$, the ICC is more difficult to satisfy as V becomes larger. This implies that as the value of winning future competition becomes more important, the core technology will be transferred less often. These predictions are consistent with the protectionist arguments that advocate safeguarding the cutting-edge technology.

However, it is important to understand why transferring the core technology becomes less attractive for the licensor as the probability of leapfrogging and the value of future competition get larger. A simple explanation that the licensor gets more cautious in safeguarding her frontier technology to maintain her dominant position begs the question of why the expected loss of the licensor cannot be compensated via a fixed fee if the licensee's competitive gains come at the expense of the licensor. Indeed, in Proposition 3, I demonstrated that any loss of competitive edge that accompanies the transfer of the core technology can be compensated via a fixed fee. In my model, the reason lies in the cost of satisfying the ex post ICC due to the inability to write a complete contract. According to my model, therefore, it is not a mistake for the licensor to transfer the core technology even when she loses future competition to the licensee to whom her core technology has been transferred. It could have been a calculated risk taken by a rational decision-maker.

My model can also shed some light on the mechanism by which a "grant-back" clause can facilitate the transfer of the core technology; it relaxes the ICC. To analyze the effect of the grant-back clause on the incentive to transfer the core technology, let me assume that $\mathrm{V}$ comprises two components, $V_{B}$ and $V_{S}\left(V=V_{B}+V_{S}\right)$. $V_{B}$ and $V_{S}$ denote the values of the new product in the licensee's and licensor's local markets, respectively. The grant-back clause 
stipulates that any improvements derived from the licensed technology by the licensee be assigned to the licensor. However, they may be used by the licensee without any additional licensee fee or royalty (Areeda [1981]). In such an event, the licensor and licensee will capture their own local markets if we assume a Bertrand type competition and a small sunk cost of entry into the other's market. Therefore, with the inclusion of the "grant-back" clause in the licensing contract, the future payoffs from transferring the core technology $\operatorname{are}^{24}$ :

$$
\widetilde{\phi}_{S}^{C O R E}=(1-\theta) \mathrm{V}+\theta \mathrm{V}_{\mathrm{S}}, \quad \widetilde{\phi}_{B}^{C O R E}=\theta \mathrm{V}_{\mathrm{B}}
$$

The future payoff from the peripheral technology is the same as before $\left(\widetilde{\phi}_{S}^{\text {PERI }}=\phi_{S}^{\text {PERI }}=\mathrm{V}, \widetilde{\phi}_{B}^{\text {PERI }}\right.$ $=\phi_{B}^{P E R I}=0$ ) because the grant-back clause has no consequences in this case.

The ICC for the licensor to transfer the core technology can be rewritten as:

$$
\begin{aligned}
& R^{C O R E}(\mathrm{r})+\tilde{\phi}_{S}^{C O R E} \geq R^{P E R I}(\mathrm{r})+\tilde{\phi}_{S}^{P E R I}, \text { or } \\
& R^{C O R E}(\mathrm{r})-R^{P E R I}(\mathrm{r})=\mathrm{r}[\mathrm{q}(\underline{c}+\mathrm{r})-\mathrm{q}(\bar{c}+\mathrm{r})] \geq \theta \mathrm{V}_{\mathrm{B}}=\widetilde{\phi}_{S}^{P E R I}-\widetilde{\phi}_{S}^{C O R E}
\end{aligned}
$$

Let $\widetilde{r}^{*}(\theta)$ be the minimum royalty rate to satisfy the ICC given the probability of losing future competition $\theta$. Since the incentive compatibility has been relaxed with the grant-back clause $\left(\mathrm{V}_{\mathrm{B}}<\mathrm{V}\right)$, we have $\widetilde{r}^{*}(\theta)<\mathrm{r}^{*}(\theta)$. The payoff from transferring the core technology can be written as:

$$
\widetilde{\Pi}^{\mathrm{CORE}}(\theta)=\pi\left[\underline{c}+\tilde{r}^{*}(\theta)\right]+\mathrm{r}^{*}(\theta) \mathrm{q}[\underline{c}+\widetilde{r} *(\theta)]+\mathrm{V}
$$

The payoff from transferring the peripheral technology is the same as before:

$$
\widetilde{\Pi}^{\text {PERI }}(\theta)=\Pi^{\text {PERI }}(\theta)=\pi(\bar{c})+\mathrm{V}
$$

Let $\widetilde{\theta}^{*}$ be the unique value such that $\widetilde{\Pi}^{C O R E}(\theta)>\widetilde{\Pi}^{P E R I}(\theta)$ if and only if $\theta<\widetilde{\theta} *$. The fact that $\tilde{r}^{*}(\theta)<\mathrm{r}^{*}(\theta)$ implies that $\tilde{\theta} *>\theta^{*}$. Consequently, grant-back clauses can be beneficial for the licensor in two respects. First, the grant-back clause allows the core technology to be transferred for a wider range of parameters. For parameter values $\theta \in\left(\theta^{*}, \widetilde{\theta}\right.$ ], the core technology will not be transferred without the grant-back clause. Second, for $\theta<\theta^{*}$, the grantback clause is not necessary for the core technology to be transferred. The grantback clause, however, reduces the royalty rate and induces a more efficient output level (see Figure 2).

24 Variables corresponding to the case with a grant-back clause are denoted with tilde. 


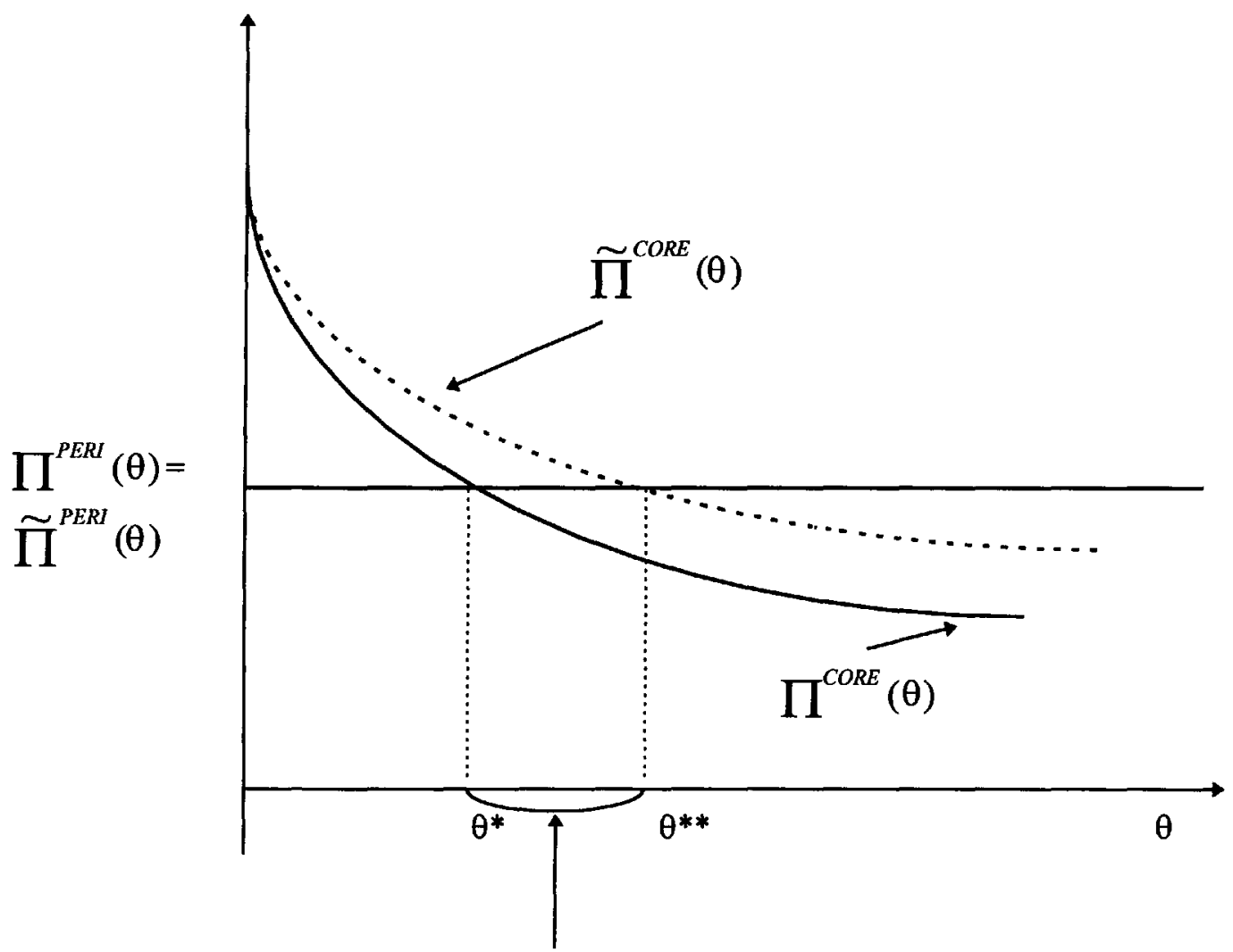

The parameter region in which the inclusion of the grant-back clause is needed for the core technology to be transferred.

Figure 2. The Effect of the Grant-Back Clause in the Licensing of the Core Technology

Proposition 4. Inclusion of a royalty rate is necessary for the transfer of the core technology to be ex post incentive-compatible if the type of technology to be trasnferred cannot be specified in the contract. As the value of winning future competition becomes more important, the incentive compatibility constraint becomes more costly to satisfy. As a result, the transfer of core technology is observed less often. Grantback clauses allow the core technology to be transferred in a wider parameter space by relaxing the ICC.

It should be mentioned that my model abstracted from two important considerations in the analysis of the grant-back clause. First, the model was devoid of any strategic R\&D competition; innovation was implicitly assumed to occur by chance. Therefore, the only effect of the grant-back clause was an indirect one; grant-back clauses relax the ICC, which in turn 
affects the current production decision through the royalty rate. If I introduce R\&D costs which vary with the intensity level, the inclusion of the grant-back clause may have the direct effect of dulling the incentive for the licensee to engage in $R \& D$. In this case, there may be an additional incentive to include the grant-back clause to avoid rent dissipation in R\&D competition. However, this may be socially harmful if the outcome is a collusive level of R\&D. Second, innovation was assumed to occur anyway regardless of the number of firms capable of innovating. Also by ignoring discounting, the R\&D game had the feature of a constant-sum game. Only who develops first matters, not when the innovation actually occurs. If we amend the game to account for these omissions, the merit of licensing the core technology vs. the peripheral technology will depend on the tradeoff between duplication and diversification in the R\&D process.

\section{Concluding Remarks}

The market for information is replete with imperfection and this is reflected in the structure of licensing agreements. In this paper, I develope an incomplete contract model of technology transfer that accounts for market imperfection. More specifically, noncontractible aspects of technology transfer that have been largely ignored in the literature, are explicitly introduced in the analysis of licensing. The result is a framework that brings the model of licensing closer to reality and generates predictions consistent with empirical findings.

First of all, the introduction of inputs that are not contractible and costly explains the prevalence of royalty contracts in the licensing relationship. Moreover the model was able to relate the size of the royalty rate to the parameters that represent the circumstances under which the concerned parties operate. The framework also provides a rigorous evaluation of the recent debate over the issue of technology licensing and competitiveness in the global economy. In addition, the difficulty that the licensor faces in controlling the use of information in the development of related products in the future can also explain the rationale for including grantback clauses in licensing contracts. Finally, the model can be naturally extended to analyze the choice of a technology holder between direct investment and licensing in an attempt to serve a foreign market.

My model may have implications for the dynamics in the formulation and implementation of technology policy for developing countries, which often pursue active government policies aimed at the creation of indigenous capacity. In fear of foreign dependency and/or for the purpose of strengthening the bargaining power of domestic firms, governments often require their own approval of foreign licensing agreements. In the approval process, governments 
restrict the type of contracts in order to preclude constraints that may be imposed by foreign nationals on local firms' efforts to develop their own capability. However, as the economy matures and threatens to be a competitor to potential licensors, it may even be necessary to allow foreign suppliers greater control and favorable terms in order to have any chance of securing continued access to advanced foreign technologies; it may be counterproductive to insist on restrictive technology policy as the economy matures. In this respect, it is illuminating to observe that in the beginning of 1980 Korea abolished all restrictions imposed on terms and conditions of foreign licensing as it found it increasingly difficult to obtain state-of-the-art technologies [see Kim and Dahlman (1992)]. 25

In order to focus on the implications of the cost of transfer for optimal contractual forms, I considered the licensing relationship between two firms serving segmented markets. This paper, therefore, deliberately ignored the effect of payoff interdependence that can arise from downstream competition between the licensor and licensee or among potential licensees, which was the main concern in the traditional licensing literature [see, for example, Katz and Shapiro (1985), Kamien and Tauman (1986), Gallini and Winter (1985), etc.]. To merge these two distinct but complementary approaches would be a logical step for future research.

\footnotetext{
${ }^{25}$ In the face of increasing reluctance to transfer technology by firms in industrially-advanced countries, Korean firms also resorted to the strategy of setting up "antennas" which serve as technological outposts. For example, several Korean firms (especially major chaebols) have set up outposts in Silicon Valley to leapfrog into state-of-the-art technologies by monitoring technological changes and to acquire advanced semiconductor and computer technologies [see Kim (1993)].
} 


\section{References}

Aghion, Philippe and Patrick Bolton, "An Incomplete Contract Approach to Financial Contracting," Review of Economic Studies, LIX (1992), 473-94.

Aghion, Philippe and Jean Tirole, "The Management of Innovation, " Quarterly Journal of Economics, 1994, 1185-1209.

Areeda, Phillip, Antitrust Analysis, Little, Brown and Company, Boston, 1981.

Arrow, Kenneth, "Economic Welfare and the Allocation of Resources for Inventions," in Richard Nelson (ed.), The Rate and Direction of Inventive Activity, Princeton University Press, 1962.

Barton, John H., Robert B. Dellenbach, and Paul Kuruk, "Toward a Theory of Technology Licensing," Stanford Journal of International Law (25), 1988, 195-229.

Berrill, K. (ed.), Economic Development with Special Reference to East Asia, St. Martin Press, New York, 1964.

Caves, Richard E., Multinational Enterprise and Economic Analysis, Cambridge University Press, 1982.

Caves, R., Crookell, H. and J.P. Killing, The Imperfect Market for Technology Licenses," Oxford Bulletin of Economics and Statistics (45), 1983, 223-248.

Cohen, Wesley M. and Daniel A. Levinthal, "Innovation and Learning: The Two Faces of R\&D," Economic Journal (99), 1989, 569-596.

Dertouzos, Michael L., Richard K.Lester, and Robert M. Solow, Made in America: Regaining the Productive Edge, Cambridge, MIT Press, 1989.

Firestone, O., Economic Implications of Patents, University of Ottawa Press, 1971. 
Gallini, Nancy T., and Ralph Winter, "Licensing in the Theory of Innovation," Rand Journal of Economics (16), 1985, 237-252.

Gallini, Nancy T. and Brian D. Wright, "Technology Transfer under Asymmetric Information," Rand Journal of Economics (21), 1990, 147-160.

Grossman, Gene and Elhanan Helpman, Innovation and Growth in the Global Economy, The MIT Press, Cambridge, 1991.

Grossman, Sanford and Oliver Hart, "The Costs and Benefits of Ownership: A Theory of Lateral and Vertical Integration, Journal of Political Economy (94), 1986, 691-719.

Holmstrom, Bengt, "Moral Hazard in Teams," Bell Journal of Economics (3), 1982, 324-340.

Horstman, Ignatius and James R. Markusen, "Licensing versus Direct Investment: A Model of Internalization by the Multinational Enterprise," Canadian Journal of Economics (20), $1987,464-481$.

Horstman, Ignatius and James R. Markusen, "Exploring New Markets: Direct Investment, Contractual Relations and the Multinational Enterprise," NBER Working Paper No. $5029,1995$.

Kamien, Morton I., "Patent Licensing," in Robert J. Aumann and Sergiu Hart (ed.), Handbook of Game Theory, Vol.1, Elsevier Science Publishers B.V., 1992.

Kamien, Morton I. and Yair Tauman, "Fees versus Royalties and the Private Value of a Patent," Quarterly Journal of Economics (101), 1986, 471-491.

Katz, Michael and Carl Shapiro, "On the Licensing of Innovations," Rand Journal of Economics (16), 1985, 504-520.

Kim, Linsu, "Absorptive Capacity and Industrial Growth: A Conceptual Framework and Korea's 
Experience," East Asian Institute Reports, Columbia University, March 1993.

Kim, Linsu and Carl J. Dahlman, "Technology Policy for Industrializatio: An Integrative Framework and Korea's Experience," Research Policy (21), 1992, 437-452.

Markusen, James R., "The Boundaries of Multinational Enterprises and the Theory of International Trade," Journal of Economic Perspectives (9), 1995, 169-189.

Rockett, Katherine, "The Quality of the Licensed Technology," International Journal of Industrial Organization (8), 1990, 559-574.

Rostoker, M., "A Survey of Corporate Licensing," IDEA (24), 1984, 59-92.

Rothstein, Paul M. and Eric H. Willgohs, "Summary of Proceedings of the Symposium on the Law and Economics of International Technology Licensing," Stanford Journal of International Law (25), 1988, 231-256.

Shapiro, Carl, "Patent Licensing and R\&D Rivalry," American Economic Review (75), 1985, pp.25-30.

Taylor, Charles T. and Z. A. Silberston, The Economic Impact of the Patent System: A Study of the British Experience, Cambridge University Press, 1973.

Teece, David J., Technology Transfer by Multinational Firms: The Resource Cost of Transferring Technological Know-How," Economic Journal (87), 1977, 242-61 


\section{Appendix}

This appendix proves that $\sigma^{\prime}(r)>0$ for sufficiently small values of positive $r$ if we assume that the Nash equilibrium in the choice of effort level is stable. The equilibrium in effort levels by the licensor and the licensee with the royalty rate $r,(\sigma(r), \beta(r))$, is defined by the pair of firstorder conditions (4) and (5). Totally differentiating these first-order conditions gives us:

$$
\left[\begin{array}{ll}
\frac{\partial^{2} \psi^{s}}{\partial \sigma^{2}} & \frac{\partial^{2} \psi^{s}}{\partial \sigma \partial \beta} \\
\frac{\partial^{2} \psi^{B}}{\partial \sigma \partial \beta} & \frac{\partial^{2} \psi^{B}}{\partial \beta^{2}}
\end{array}\right]\left[\begin{array}{l}
\sigma^{\prime}(r) \\
\beta^{\prime}(r)
\end{array}\right]=\left[\begin{array}{c}
-\frac{\partial^{2} \psi^{s}}{\partial \sigma \partial r} \\
-\frac{\partial^{2} \psi^{B}}{\partial \beta \partial r}
\end{array}\right]
$$

where

$$
\begin{aligned}
& \frac{\partial^{2} \psi^{s}}{\partial \sigma^{2}}=\mathrm{rq}\left(\frac{\partial c}{\partial \sigma}\right)^{2}+\mathrm{rq}^{\prime} \frac{\partial^{2} c}{\partial \sigma^{2}}<0 \text { (by the second order condition) } \\
& \frac{\partial^{2} \psi^{B}}{\partial \beta^{2}}=-\mathrm{q}^{\prime}\left(\frac{\partial c}{\partial \beta}\right)^{2}-\mathrm{q} \frac{\partial^{2} c}{\partial \beta^{2}}<0 \text { (by the second order conditon) } \\
& \frac{\partial^{2} \psi^{s}}{\partial \sigma \partial \beta}=\mathrm{rq}^{\prime \prime} \frac{\partial c}{\partial \sigma} \frac{\partial c}{\partial \beta}+\mathrm{rq}^{\prime} \frac{\partial^{2} c}{\partial \sigma \partial \beta} \\
& \frac{\partial^{2} \psi^{B}}{\partial \sigma \partial \beta}=-\mathrm{q}^{\prime} \frac{\partial c}{\partial \sigma} \frac{\partial c}{\partial \beta}-\mathrm{q} \frac{\partial^{2} c}{\partial \sigma \partial \beta} \\
& \frac{\partial^{2} \psi^{s}}{\partial \sigma \partial r}=\left(\mathrm{q}^{\prime}+\mathrm{rq}\right) \frac{\partial c}{\partial \sigma} \\
& \frac{\partial^{2} \psi^{B}}{\partial \beta \partial r}=-\mathrm{q}^{\prime} \frac{\partial c}{\partial \beta}
\end{aligned}
$$

It is readily seen that $\sigma^{\prime}(\mathrm{r})$ can be written as

$$
\sigma^{\prime}(\mathrm{r})=\frac{\left[\begin{array}{cc}
-\frac{\partial^{2} \psi^{s}}{\partial \sigma \partial r} & \frac{\partial^{2} \psi^{s}}{\partial \sigma \partial \beta} \\
-\frac{\partial^{2} \psi^{B}}{\partial \beta \partial r} & \frac{\partial^{2} \psi^{B}}{\partial \beta^{2}}
\end{array}\right]}{\Delta}
$$

where $\Delta=\frac{\partial^{2} \psi^{S}}{\partial \sigma^{2}} \frac{\partial^{2} \psi^{B}}{\partial \beta^{2}}-\frac{\partial^{2} \psi^{S}}{\partial \sigma \partial \beta} \frac{\partial^{2} \psi^{B}}{\partial \sigma \partial \beta}$. The stability of equilibrium effort levels requires that $\Delta>0$. Therefore, the sign of $\sigma^{\prime}(r)$ is the same as the sign of the numerator in Eq. (A.2), which 
is:

$$
\begin{aligned}
-\frac{\partial^{2} \psi^{S}}{\partial \sigma \partial r} \frac{\partial^{2} \psi^{B}}{\partial \beta^{2}} & +\frac{\partial^{2} \psi^{S}}{\partial \sigma \partial \beta} \frac{\partial^{2} \psi^{B}}{\partial \beta \partial r}=\left(\left(\mathrm{q}^{\prime}+\mathrm{rq}\right) \frac{\partial c}{\partial \sigma}\right)\left(\mathrm{q}^{\prime}\left(\frac{\partial c}{\partial \beta}\right)^{2}+\mathrm{q} \frac{\partial^{2} c}{\partial \beta^{2}}\right) \\
& -\left(\mathrm{rq}^{\prime \prime} \frac{\partial c}{\partial \sigma} \frac{\partial c}{\partial \beta}+\mathrm{rq}^{\prime} \frac{\partial^{2} c}{\partial \sigma \partial \beta}\right)\left(\mathrm{q}^{\prime} \frac{\partial c}{\partial \beta}\right)
\end{aligned}
$$

For $r$ sufficiently close to zero, the value of the numerator, (A.3), can be approximated by $\mathrm{q}^{\prime}\left(\mathrm{q}^{\prime}\left(\frac{\partial c}{\partial \beta}\right)^{2}+\mathrm{q} \frac{\partial^{2} c}{\partial \beta^{2}}\right)$, which is positive since the expression in the bracket is negative by the second order condition. 


\section{4-1995 Discussion Paper Series}

Department of Economics

Columbia University

1022 International Affairs Bldg.

420 West 118th Street

New York, N.Y., 10027

The following papers are published in the 1994-95 Columbia University Discussion Paper series which runs from early November to October 31 (Academic Year). Domestic orders for discussion papers are available for purchase at $\$ 8.00$ (US) each and $\$ 140.00$ (US) for the series. Foreign orders cost $\$ 10.00$ (US) for individual paper and $\$ 185.00$ for the series. To order discussion papers, please send your check or money order payable to Department of Economics, Columbia University to the above address. Be sure to include the series number for the paper when you place an order.

708. Trade and Wages: Choosing among Alternative Explanations Jagdish Bhagwati

709. Dynamics of Canadian Welfare Participation

Garrey F. Barret, Michael I. Cragg

710. Much Ado About Nothing? Capital Market Reaction to Changes in Antitrust Precedent concerning Exclusive Territories.

Sherry A. Glied, Randall S. Kroszner

711. The Cost of Diabetes

Matthew Kahn

712. Evidence on Unobserved Polluter Abatement Effort

Matthew E. Kahn

713. The Premium for Skills: Evidence from Mexico

Michael Cragg

714. Measuring the Incentive to be Homeless

Michael Cragg, Mario Epelaum

715. The WTO: What Next?

Jagdish Bhagwati

716. Do Converters Facilitate the Transition to a New Incompatible Technology?

A Dynamic Analysis of Converters

Jay Phil Choi

716A. Shock Therapy and After: Prospects for Russian Reform

Padma Desai

717. Wealth Effects, Distribution and The Theory of Organization

-Andrew F. Newman and Patrick Legros 
1994-95 Discussion Paper Series

718. Trade and the Environment: Does Environmental Diversity Detract from the Case for Free Trade?

-Jagdish Bhagwati and T.N. Srinivasan (Yale Univ)

719. US Trade Policy: Successes and Failures

-Jagdish Bhagwati

720. Distribution of the Disinflation of Prices in 1990-91 Compared with Previous Business Cycles

-Philip Cagan

721. Consequences of Discretion in the Formation of Commodities Policy

-John McLaren

722. The Provision of (Two-Way) Converters in the Transition Process to a New Incompatible Technology

-Jay Pil Choi

723. Globalization, Sovereignty and Democracy

-Jagdish Bhagwati

724. Preemptive R\&D, Rent Dissipation and the "Leverage Theory"

-Jay Pil Choi

725. The WTO's Agenda: Environment and Labour Standards, Competition Policy and the Question of Regionalism

-Jagdish Bhagwati

726. US Trade Policy: The Infatuation with FTAs

-Jagdish Bhagwati

727. Democracy and Development: New Thinking on an Old Question

-Jagdish Bhagwati

728. The AIDS Epidemic and Economic Policy Analysis

-David E. Bloom, Ajay S. Mahal

729. Economics of the Generation and Management of Municipal Solid Waste

-David E. Bloom, David N. Beede

730. Does the AIDS Epidemic Really Threaten Economic Growth?

-David E. Bloom, Ajay S. Mahal

731. Big-City Governments

-Brendan O'Flaherty

732. International Public Opinion on the Environment

-David Bloom 
733. Is an Integrated Regional Labor Market Emerging in the East and Southeast Asia? -David Bloom, Waseem Noor

734. Migration, Integration and Development -Abhijit V. Banerjee, Andrew Newman

735. Infrastructure, Human Capital and International Trade -Ronald Findlay

736. Short Ballots: Why Mayors Are in Charge of So Many Different Things -Brendan O'Flaherty

737. Demand for Environmental Goods: Evidence from Voting Patterns on California Initiatives -Matthew Kahn and John Matsusaka

738. Inflation and Stabilization in Poland 1990 - 1995 -S.Wellisz

739. Particulate Pollution Trends in the 1980's -M. Kahn

740. Why has Wage Dispersion Grown in Mexico? Is it the Incidence of Reforms or the Growing Demand for Skills?

-M.I. Cragg and M. Epelbaum

741. Russia's Transition Toward the World Economy: -P. Desai

742. Poland: Transition and Integration in the World Economy $-S$. Wellisz

743. Team Effects on Compensation: An Application to Salary Determination in the National Hockey League -T. Idson and L.H. Kahane

744. Economic Development, Growth of Human Capital, and the Dynamics of theWage Structure -J. Mincer

745. Technology Transfer with Moral Hazard -J.P. Choi (Oct.) 